\title{
Prescribing Patterns of Methylphenidate and Atomoxetine for Patients with Attention-Deficit/Hyperactivity Disorder
}

\author{
Ilse Truter \\ Drug Utilisation Research Unit (DURU), Department of Pharmacy, Nelson Mandela Metropolitan University (NMMU), Port \\ Elizabeth, South Africa \\ *For correspondence: Email: ilse.truter@nmmu.ac.za; Tel: + 27-41-5042131; Fax: + 27-41-5042744
}

\begin{abstract}
Purpose: To determine the prescribing pattern of methylphenidate and atomoxetine to patients with Attention-Deficit/Hyperactivity Disorder (ADHD) in South Africa.

Methods: A retrospective, cross-sectional pharmacoepidemiological study was conducted based on the data from a medical aid administrator in South Africa for 2011. All records for ADHD patients who received one or more prescriptions for methylphenidate and/or atomoxetine (ATC Code N06BA) were extracted for analysis.

Results: A total of 455 patients (mean age: $16.5 \pm 11.56$ yr) received 1653 prescriptions for methylphenidate and/or atomoxetine at a total cost of South African Rand 554,915.84 (US dollar 1.0 = Rand 6.76). A majority of these patients (70.34\%) were males and $21.10 \%$ were older than $18 \mathrm{yr}$ (25.76 \% of females and $19.81 \%$ of males). About a third of the prescriptions (30.44 \%) were dispensed to children younger than 12 years while $25.88 \%$ were dispensed to adolescents (12 to 18 years). Most prescriptions (92.01\%) were for methylphenidate while atomoxetine accounted for $7.99 \%$ of the prescription. A majority of the prescriptions for methylphenidate (47.86\%) were for children younger than $12 \mathrm{yr}$, and most prescriptions for atomoxetine (52.27\%) were for adolescents.

Conclusion: Methylphenidate is the mainstay in the treatment of ADHD in South Africa, with atomoxetine prescribed more often to older patients. Drug use is rational and dosages are within the recommended dosage ranges. As expected, older patients are receiving treatment for ADHD.
\end{abstract}

Keywords: Methylphenidate, Atomoxetine, Attention-Deficit/Hyperactivity disorder, Pharmacoepidemiology

Tropical Journal of Pharmaceutical Research is indexed by Science Citation Index (SciSearch), Scopus, International Pharmaceutical Abstract, Chemical Abstracts, Embase, Index Copernicus, EBSCO, African Index Medicus, JournalSeek, Journal Citation Reports/Science Edition, Directory of Open Access Journals (DOAJ), African Journal Online, Bioline International, Open-J-Gate and Pharmacy Abstracts

\section{INTRODUCTION}

Attention-deficit/hyperactivity disorder (ADHD) is one of the most commonly diagnosed and treated psychiatric disorders in children. Epidemiological studies have reported that 4 to 5 $\%$ of children in the United States, New Zealand/Australia, Germany and Brazil suffer from ADHD [1]. Prospective, longitudinal followup studies have reported that the symptoms of ADHD persist into adulthood at rates varying from 4 to $60 \%$ [2-5]. Studies suggest that between one- and two-thirds of those children diagnosed with ADHD (1 to $6 \%$ of the general population) continue to manifest symptoms of ADHD as adults [6]. While syndromal persistence is relatively low, symptom persistence and impairment is high [7].

Approximately 200 clinical trials to date [8] document the efficacy of stimulants for ADHD in the child and adolescent population, and several 
systematic reviews $[9,10]$ indicate that stimulant medications are efficacious in the treatment of children and adolescents with ADHD. In contrast to the data on psychostimulants in children and adolescents diagnosed with ADHD, the evidence for stimulants in adult ADHD is much smaller. Furthermore, the trials assessing efficacy of methylphenidate treatment in adults with ADHD, have shown ambiguous results.

ADHD is increasingly being diagnosed in adult patients in South Africa but only few have focused on ADHD prescribing to patients of all age groups in the country. The primary aim of the study was therefore to determine the prescribing pattern of methylphenidate and atomoxetine to patients in a South African patient population.

\section{EXPERIMENTAL}

\section{Research design}

A retrospective, cross-sectional pharmacoepidemiological study was conducted on data of a medical aid administrator in South Africa for 2011. There are several medical aid administrators in South Africa who administer data for groups of medical aid (medical insurance) schemes. They therefore perform the administrative functions for the medical aid schemes. The database contained 2,298,312 records of medicines, procedures and medical devices. All records for patients who received one or more prescriptions for methylphenidate and/or atomoxetine (ATC Code N06BA) [11] were extracted for analysis. Each medication record contained information on the age and gender of the patient, with a unique number to identify each patient, the date of the prescription, detailed information on the dispensed drug (name, package size, formulation, strength and quantity) and amount paid. The South African Medicines Formulary [12] and MIMS [13] were used to identify and classify medicine into therapeutic groups.

\section{Data analysis}

Records were categorized on the basis of age as children (< $12 \mathrm{yr}$ ), adolescents (12 - $18 \mathrm{yr}$ ) and adults (> $18 \mathrm{yr})$.

This cost (part of the database records) represented the amount that was paid by the medical aid scheme for each product. As at the time of the study (30 June 2011), one US dollar
(\$1.00) was equal to 6.76 South African Rand (R).

Microsoft Excel $®$ and Statistica $®$ were used for statistical analyses. Basic descriptive and inferential statistics were calculated. The results are expressed as mean \pm standard deviation. Chi-square test was used to detect significant differences between female and male patients in the different age groups, as well as to detect differences in prescribing frequency of products between atomoxetine and methylphenidate in the different age groups. A value of $p<0.05$ was considered significant.

\section{Ethical approval}

Ethical approval to conduct studies on prescription databases has been obtained from the Research Ethics Committee (Human) of the Nelson Mandela Metropolitan University (ethics clearance number: H08-HEA-PHA-005).

\section{RESULTS}

\section{Patient demographic information}

A total of 445 patients received 1,653 prescriptions for methylphenidate and/or atomoxetine at an average cost of R 335.70 per product (the total amount paid was $R$ $554,915.84)$. The average age of patients was $16.50 \pm 11.56$ years. The age and gender distribution of patients are given in Figure 1. Nearly three-quarters of patients $(70.34 \%)$ were males $\left(x^{2}=2.010 ; \mathrm{df}=2 ; p<0.5\right)$. A fifth of patients $(21.10 \%)$ were adults or older than 18 years (34 patients or $25.76 \%$ of female patients, and 62 patients or $19.81 \%$ of male patients).

\section{Overall prescribing frequency}

Patients were dispensed an average of $3.71 \pm$ 2.89 products during the year. They were therefore not all receiving the products every month of the year on a consecutive basis, and further investigation indicated that there were breaks in treatment (for example, a patient receiving a product for two months, then no product for the next month, and then again receiving a product). Patients were therefore not using these products on a chronic or continuous basis. Male patients younger than 20 years received disproportionally more products than female patients. A third of prescriptions (30.44 $\%$ ) were dispensed to children younger than 12 years, and $25.88 \%$ were dispensed to adolescents. 


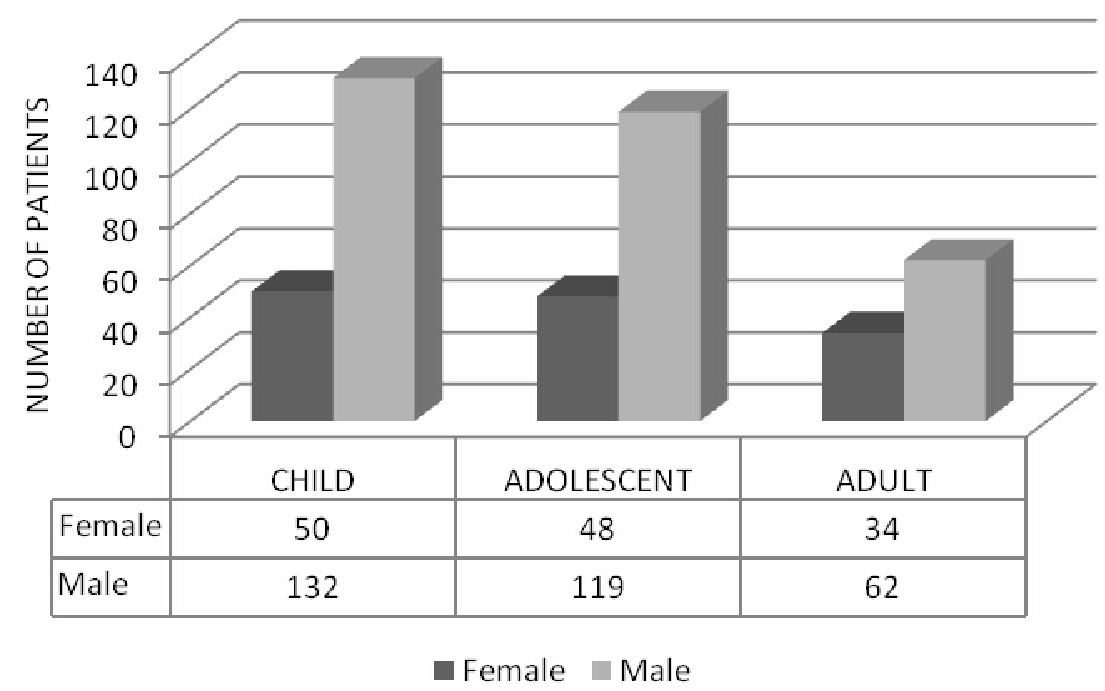

Figure 1: Number of ADHD patients in each age and gender group $(\mathrm{n}=445)^{*} ;{ }^{*} \chi^{2}=2.010 ;$ d.f. $=2 ; p<0.5$

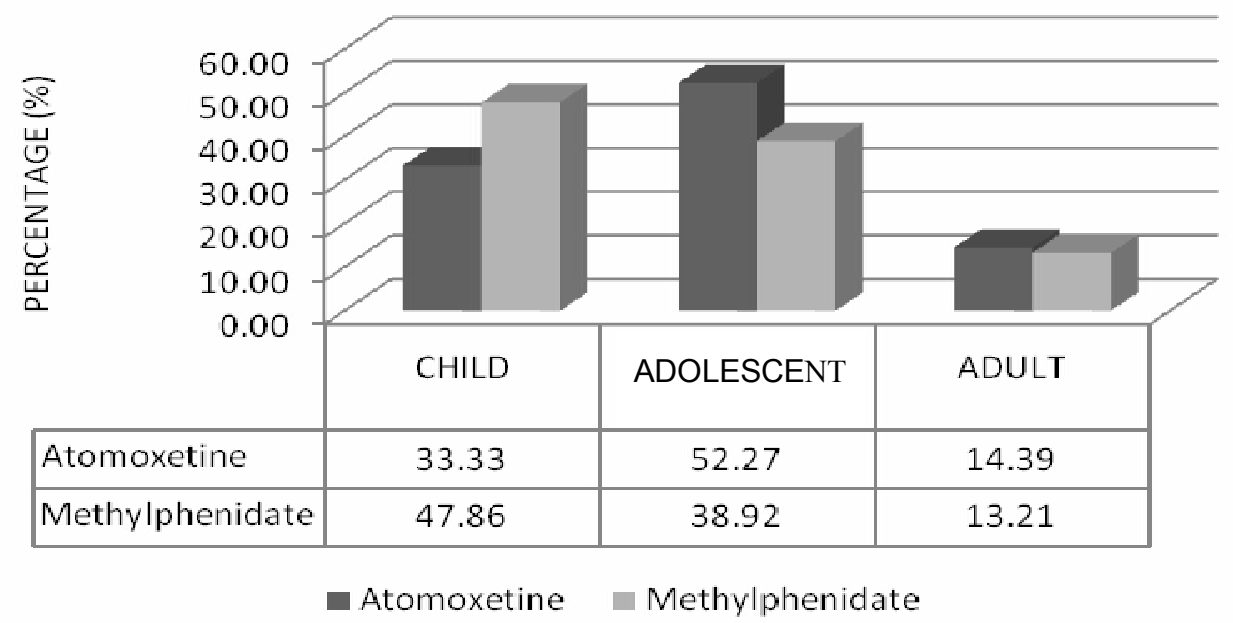

Figure 2: Percentage prescribing of the two active ingredients to the different age groups $(\mathrm{n}=1653)^{*} ;{ }^{*} \chi^{2}=$ 11.031; d.f. $=2 ; p<0.005$

\section{Prescribing of active ingredients}

Most prescriptions were for methylphenidate $(92.01 \%)$, followed by atomoxetine $(7.99 \%)$. The percentage prescribing of atomoxetine and methylphenidate to the different age groups is given in Figure $2\left(x^{2}=11.031\right.$; d.f. $=2 ; p<$ $0.005)$. Most prescriptions for methylphenidate $(47.86 \%)$ were for children younger than 12 years of age, and most prescriptions for atomoxetine $(52.27 \%)$ were for adolescents (12 to 18 years).

The number of each branded product prescribed was analysed. There were three different trade name products of methylphenidate prescribed, namely Concerta ${ }^{\circledR}$ SRT $(18 \mathrm{mg}, 27 \mathrm{mg}, 36 \mathrm{mg}$ and $54 \mathrm{mg}$ ), Methylphenidate $\mathrm{HCl}$-Douglas $\AA$ (10 $\mathrm{mg}$ ) tablets, and Ritalin ${ }^{\circledR}(10 \mathrm{mg})$ tablets and Ritalin LA® $(20 \mathrm{mg}, 30 \mathrm{mg}$ and $40 \mathrm{mg}$ ) capsules. Methylphenidate $\mathrm{HCl}$-Douglas $\AA(10 \mathrm{mg})$ tablets were the most frequently prescribed trade name and dosage form, accounting for $23.41 \%$ of prescriptions. Only one trade name for atomoxetine was available, namely Strattera ${ }^{\circledR}$ (10 mg, $18 \mathrm{mg}, 25 \mathrm{mg}, 40 \mathrm{mg}$ and $60 \mathrm{mg}$ ) capsules. The $25 \mathrm{mg}$ and $40 \mathrm{mg}$ dosage strengths were the most popular.

\section{Drug holiday utilisation}

A drug holiday is a period of time over which drugs are withdrawn, usually as part of a structured treatment plan to reverse ineffectiveness of a drug due to receptor desensitisation or to assess therapeutic 


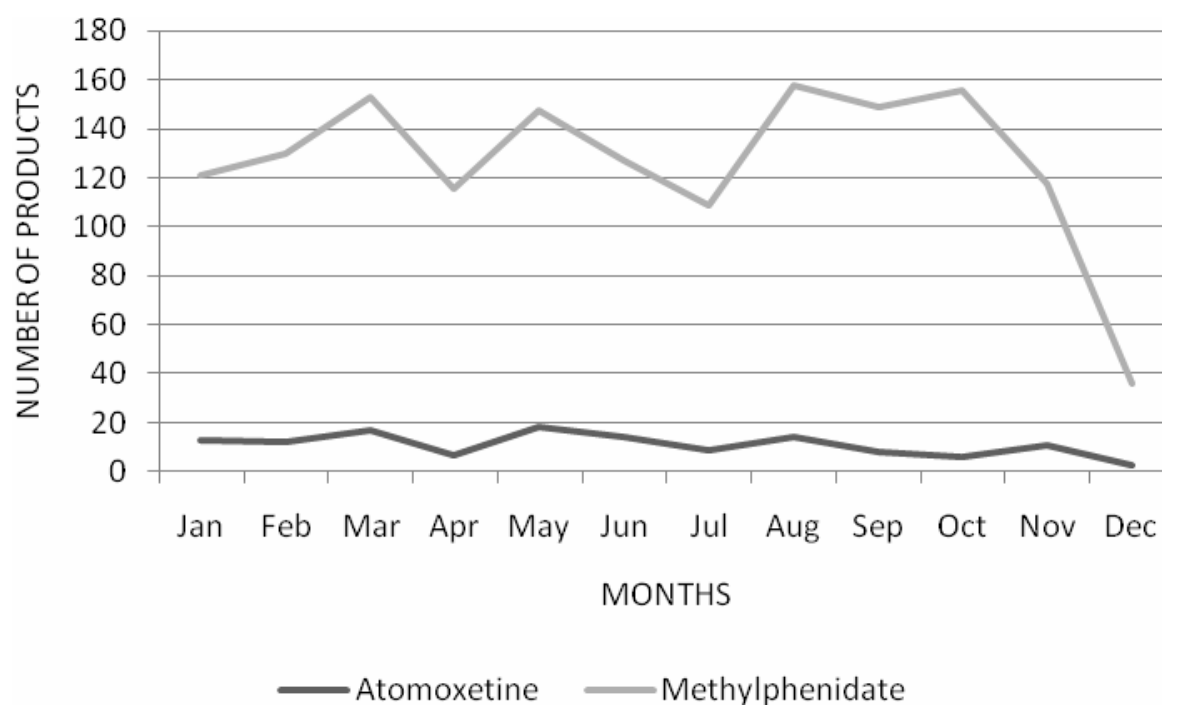

Figure 3: Prescribing frequency of methylphenidate and atomoxetine over twelve months

Table 1: DDD and average PDDs of atomoxetine and methylphenidate

\begin{tabular}{lcccc}
\hline \multirow{2}{*}{ Active Ingredient } & \multicolumn{3}{c}{ Average PDD ( \pm SD) (mg) } & DDD \\
\cline { 2 - 4 } & Female & Male & Both genders & (mg) [11] \\
\hline Atomoxetine & $37.56( \pm 21.46)$ & $35.32( \pm 15.38)$ & $35.88( \pm 17.04)$ & 80 \\
Methylphenidate & $24.68( \pm 13.58)$ & $25.83( \pm 13.23)$ & $25.48( \pm 13.34)$ & 30 \\
\hline
\end{tabular}

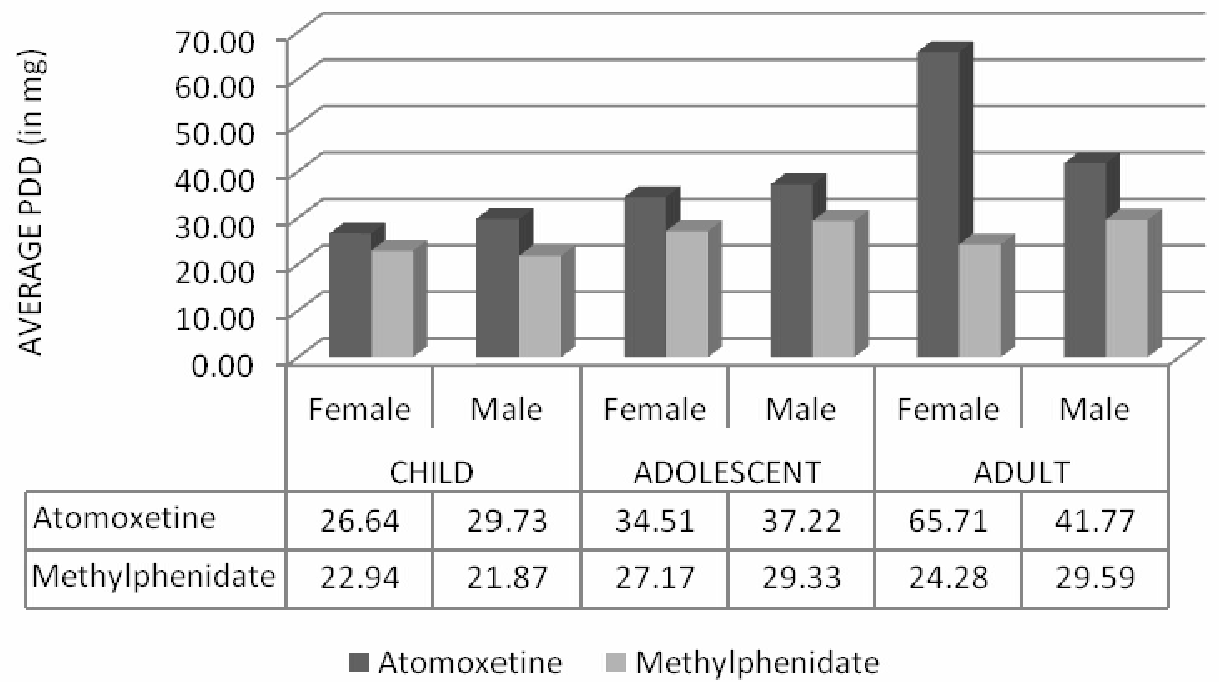

Figure 4: Average PDDs of atomoxetine and methylphenidate for the different age groups

outcomes. In ADHD, drug holidays are often utilised over weekends or holiday periods, meaning that the medication for ADHD is skipped and not used. Figure 3 indicates that peaks in the prescribing frequency of methylphenidate could be observed during March, May/June, and from August to November, indicating that drug holidays were used.

\section{Average Prescribed Daily Doses (PDDs) and Defined Daily Doses (DDDs)}

The average prescribed daily dose (PDD) for methylphenidate was $25.48 \mathrm{mg}$ and for atomoxetine $35.88 \mathrm{mg}$ (see Table 1). The respective Defined Daily Doses (DDDs) are 30 $\mathrm{mg}$ and $80 \mathrm{mg}$ [11]. 
The average PDDs for the different age groups are shown in Figure 4. The average PDDs for atomoxetine in adult female and male patients were higher, with less variation in methylphenidate dosages between the different age groups.

\section{Other products prescribed}

A total of 11716 medicine, procedures and medical devices were prescribed to the 445 patients in the study. Other frequently prescribed drug categories (except central nervous system drugs) were respiratory system agents, antimicrobials and analgesics. Nearly half of the patients (45.62\% or 203 patients) were prescribed one or more analgesic combinations, $35.73 \%$ received penicillins, $33.93 \%$ decongestant analgesic combinations, and 31.46 $\%$ antihistamines. Corticosteroids, antitussives and expectorants, non-selective COX- inhibitors, cephalosporins, and erythromycin and other macrolides were also often prescribed.

\section{DISCUSSION}

The average age of patients was 16.50 years with nearly three-quarters of patients $(70.34 \%)$ males. Also, similar to previous South African studies [14-18], most prescriptions were for methylphenidate $(92.01 \%)$, followed by atomoxetine $(7.99 \%)$. This confirms that methylphenidate remains the mainstay in the treatment of ADHD in South Africa. Three trade name products of methylphenidate were prescribed. The advantage of having a generic equivalent for methylphenidate is the cost saving, which was evident since the generic equivalent was also the most often prescribed methylphenidate product in this study. Atomoxetine has the advantage of being effective as a single daily dose [19] and has minimal risk for abuse [20]. Yet, the fact that there are no generic equivalents available for atomoxetine on the South African market makes it in general a more expensive choice.

Clear peaks in the prescribing frequency of methylphenidate could be observed during March, May/June, and from August to November. It can therefore be indicative that drug holidays were used. There was a clear decrease in the number of methylphenidate prescriptions during November/December, traditionally the long summer holiday in South Africa. Atomoxetine is a non-stimulant medicine and drug holidays are not recommended or indicated. Similar peaks and troughs were not observed for atomoxetine.
The results were generally in agreement with previous South African studies, yet proportionally more adults (21.10\% of patients) were prescribed these products compared to previous studies. Although it was previously thought that ADHD remitted before or during adolescence, it has been estimated that more than $70 \%$ of hyperactive children continue to meet criteria for ADHD as adolescents and up to $65 \%$ as adults [9]. A change in prescribing patterns for methylphenidate and atomoxetine are therefore expected as more young adults are being put on the treatment for ADHD.

\section{Limitations of the study}

Limitations of the study were the absence of diagnoses in the database and the lack of clinical information. However, methylphenidate and atomoxetine are used nearly exclusively for the treatment of ADHD. Methylphenidate can also be used for narcolepsy, but then it is usually in older patients and not in the age categories in which the products were prescribed in this study.

\section{CONCLUSION}

Methylphenidate is the mainstay in the treatment of ADHD in South Africa, with atomoxetine prescribed more often to older patients. Drug use is rational and dosages are within the recommended dosage ranges. As expected, more older patients are receiving treatment for ADHD. Further studies should be conducted on adult patients with ADHD to determine whether these products are as effective in adults as in children. Furthermore, comprehensive cost studies, especially on adult ADHD, which also account for quality-of-life and productivity aspects are needed. ADHD is a complex disorder with many facets. Studies on the use of complementary and alternative therapies for ADHD alongside pharmacotherapy are recommended.

\section{ACKNOWLEDGEMENT}

The author thanks the Medical Aid Administrator for providing the data for the study. This work is based upon research supported by the National Research Foundation (NRF). Any opinion, findings and conclusions or recommendations expressed in this paper are those of the author and therefore the NRF do not accept any liability in regard thereto. 


\section{REFERENCES}

1. Szatmari $P$. The epidemiology of attention-deficit hyperactivity disorders. In: Weiss G, editor. Attention-Deficit Hyperactivity Disorder. Philadelphia: Saunders; 1992; pp 361-371.

2. Hechtman L. Long-term outcome in attention-deficit hyperactivity disorder. Psychiatr Clin North Am 1992; 1: 553-565.

3. Mannuzza S, Klein RG, Bessler A, Malloy P, LaPadula M. Adult outcome of hyperactive boys: Educational achievement, occupational rank and psychiatric status. Arch Gen Psychiatry 1993; 50(7): 565-576.

4. Biederman J, Faraone S, Milberger S, Curtis S, Chen L, Marrs A, Ouellette C, Moore P, Spencer T. Predictors of persistence and remission of $A D H D$ into adolescence: Results from a four-year prospective follow-up study. J Am Acad Child Adolesc Psychiatry 1996; 35(3): 343-351.

5. Fischer $M$. Persistence of $A D H D$ into adulthood: It depends on whom you ask. ADHD Reports 1997; 5 . 8-10.

6. Wender PH, Wolf LE, Wasserstein J. Adults with ADHD: An overview. Ann N Y Acad Sci 2001; 931: 1-16.

7. Faraone SV, Biederman $J$, Spencer $T$, Wilens $T$, Seidman LJ, Mick E, Doyle AE. Attentiondeficit/hyperactivity disorder in adults: An overview. Biol Psychiatry 2000; 48 (Issue 1): 9-20.

8. Spencer TJ, Biederman J, Wilens $T$, Harding $M$, O'Donnell D, Griffin S. Pharmacotherapy of attention deficit hyperactivity disorder across the lifecycle: $A$ literature review. J Am Acad Child Adolesc Psychiatry 1996; 35: 409-432.

9. Jadad AR, Boyle M, Cunningham C, Kim M, Schachar R. Treatment of attention-deficit/hyperactivity disorder. Evidence Report: Technology Assessment (Summary), 1999; i-viii.

10. Weiser M, Epstein T. Methylphenidate for attentiondeficit/hyperactivity disorder in adults. Cochrane Database of Systematic Reviews, Issue 1. Art. No. CD005041. 2005; DOI: 10.1002/14651858. CD005041.
11. ATC/DDD Index 2011. Oslo: WHO Collaborating Centre for Drug Statistics Methodology, 2011. Available from: http://www.whocc.no/atc_ddd_index/

12. Rossiter D, Ed. South African Medicines Formulary (SAMF), 10th edn. Cape Town: Health and Medical Publishing Group of the South African Medical Association, 2012.

13. Snyman JR, Ed. MIMS Monthly Index of Medical Specialities (MIMS). Saxonwold: MIMS, June 2011; 51(6): 1-2.

14. Truter I. Methylphenidate: Prescribing patterns in a South African primary care patient population. J Clin Pharm Ther 2005; 30 (Issue 1): 59-63.

15. Truter I, Kotze TJ van W. Prescribing patterns of methylphenidate in a South African patient population who are members of a private medical aid. Health $S A$ Gesondheid 2005; 10(4): 75-84.

16. Truter I. Prescribing of methylphenidate to children and adolescents in South Africa: A pharmacoepidemiological investigation. S Afr Fam Prac J 2009; 51(3): 413-417.

17. Syman S, Truter I. Attention Deficit/Hyperactivity Disorder: A preliminary study in the Nelson Mandela Metropole. Jordan J Pharm Sc 2010; 3(1): 56-62.

18. Snyman S, Truter I. Children and adolescents with Attention Deficit//Hyperactivity Disorder in the Eastern Cape, South Africa: Aetiology, diagnosis and treatment. Afr J Pharm Pharmacol 2012; 6(43): 2994-2999.

19. Michelson D, Allen AJ, Busner J, Casat C, Dunn D, Kratochvil C, Newcorn J, Sallee FR, Sangal RB, Saylor $K$, et al. Once-daily atomoxetine treatment for children and adolescents with attention deficit hyperactivity disorder: a randomized, placebocontrolled study. Am J Psychiatry 2002; 159(11): 1896-1901.

20. Heil SH, Holmes HW, Bickel WK, Higgins ST, Badger GJ, Laws HF, Faries DE. Comparison of the subjective, physiological, and psychomotor effects of atomoxetine and methylphenidate in light drug users. Drug Alcohol Depend 2002; 67(2): 149-56. 